\title{
Penetrating Wounds of the Torso
}

\author{
P Barker
}

\begin{abstract}
Penetrating trauma is on the increase as a result of interpersonal violence throughout the world. It is essential that military surgeons are familiar with such injuries and trained not only in the principles of their management, but also have first-hand operative experience before deployment in the field of conflict. More often than not, this experience is to be gained in the civilian urban setting in countries such as South Africa and the USA.

The article addresses the first requirement - the principles of management and outlines basic measures to enable those unfamiliar with penetrating wounds of the torso to make a reasonable and directed approach to dealing with these patients. It does not attempt to give definitive advice on specific injuries.
\end{abstract}

It is organised according to anatomical regions, but emphasises that this is only in order to put shape to the article; penetrating injuries frequently having no respect for anatomical boundaries. Particular attention is drawn to difficult areas such as mediastinal injuries, and to modern concepts of 'damage control' surgery and the 'abdominal compartment syndrome'. The emphasis throughout is on how to get out of trouble and where particular danger spots may be anticipated. Reference will be made to the differences that may be expected within the military environment as opposed to the civilian setting, where rapid and (usually) safe evacuation to a well-equipped secure facility may not be possible.

The article aims to raise the awareness of those involved in the care of patients with penetrating wounds of the torso that a methodical approach with a practised team of experienced individuals can salvage injuries which at first sight may seem terrifying or hopeless.

\section{Introduction}

The anatomical area of the torso is frequently underestimated, being seen as roughly the central area of the body. In fact the torso comprises the whole of the trunk and pelvis - that is the whole of the body outwith the limbs, head and neck.

While the body cavities and their contents tend to be the focus of our attention, it is easy to forget that the limbs are joined to the torso by joints of some magnitude and neurovascular bundles worthy of respect. The whole is kept more or less in alignment by the spinal column. This last statement is made to remind practitioners of the flexibility of the torso, which needs to be taken into account when assessing penetrating trauma. Bullets may travel in a straight line through the body, but frequently do not (Westaby and Stephenson 1989). If flexion and rotation of the torso are combined with the vagaries of the penetrating missile, bizarre patterns of injury may result.

For all of the reasons stated above it is therefore not always helpful to classify injuries and their management according to defined anatomical areas (chest, abdomen, pelvis, etc.,) but more appropriate to view the patient as a whole, anticipating multiple cavity injury.

This paper deals with the assessment and management of wounds to the torso. It is based on the author's experience in hospitals in South Africa, primarily the Johannesburg General Trauma Unit and The Chris Hani Hospital, Baragwanath.

\section{Initial Assessment and Management}

It may safely be assumed that the individual presenting with a knife or machete still embedded in his person is suffering from a stab wound. It is not safe to assume the same when only a puncture wound can be found. Some bullet wounds can look very similar to lacerations, particularly if tangential or oblique at the point of entry. Also, within the context of urban violence, some of the victims of trauma may have been unlucky enough to have been both shot and stabbed.

Trauma victims must also be suspected of having injuries other than the most obvious ones. While it is unlikely that a person stabbed in the abdomen will have an unstable cervical spine, he/she may have been stabbed on a roof and fallen, so cervical spine injury should not be dismissed as irrelevant until it has been excluded.

It is a surgical axiom that any weapon still within the patient should not be removed outside the operating theatre, in order to
E-mail:

philbark@dsca.gov.uk 
prevent catastrophic haemorrhage on its withdrawal.

There are a few essential questions that need to be answered in the first few minutes. Is the patient dying? If so, is he dying fast? Is there the time and equipment to investigate his injuries, or is immediate life saving surgery required?

Without labouring the point, it must be stated that the ATLS resuscitation first principles of Airway, Breathing, and Circulation apply in all of the assessments of torso injury (Advanced Trauma Life Support 1993, Rhodes 1998).

These essential priorities will not be emphasised again unless there are particular traps for the unwary that may be encountered in specific injuries.

All traumatised patients require high flow oxygen (Bishop et al 1993; Waxman et al 1994; Bishop et al 1995; Durham et al 1996; Cairns et al 1997; Kincaid et al 1998). Similarly, all traumatised patients must be prevented from developing hypothermia. Hypothermia contributes significantly to both morbidity and mortality, in addition to that caused by the injury itself (Jurkovitch et al 1987; Seekamp et al 1995; Rutherford et al 1998). Measures must be taken to reduce the risk of its development from the moment the trauma team comes in contact with the patient. The environment must be warm, intravenous fluids heated (Mitchell et al 1994; Bernado et al 1997), and the patient covered with a warm air convection blanket, such as the Bair-Hugger ${ }^{\mathrm{TM}}$. This should not prevent access to the patient for resuscitative procedures, and many now have 'windowed' panels, allowing only part of the patient to be exposed at any one time.

Almost all patients will require some radiology - particularly those who have been shot. It is good practice to place 'bullet

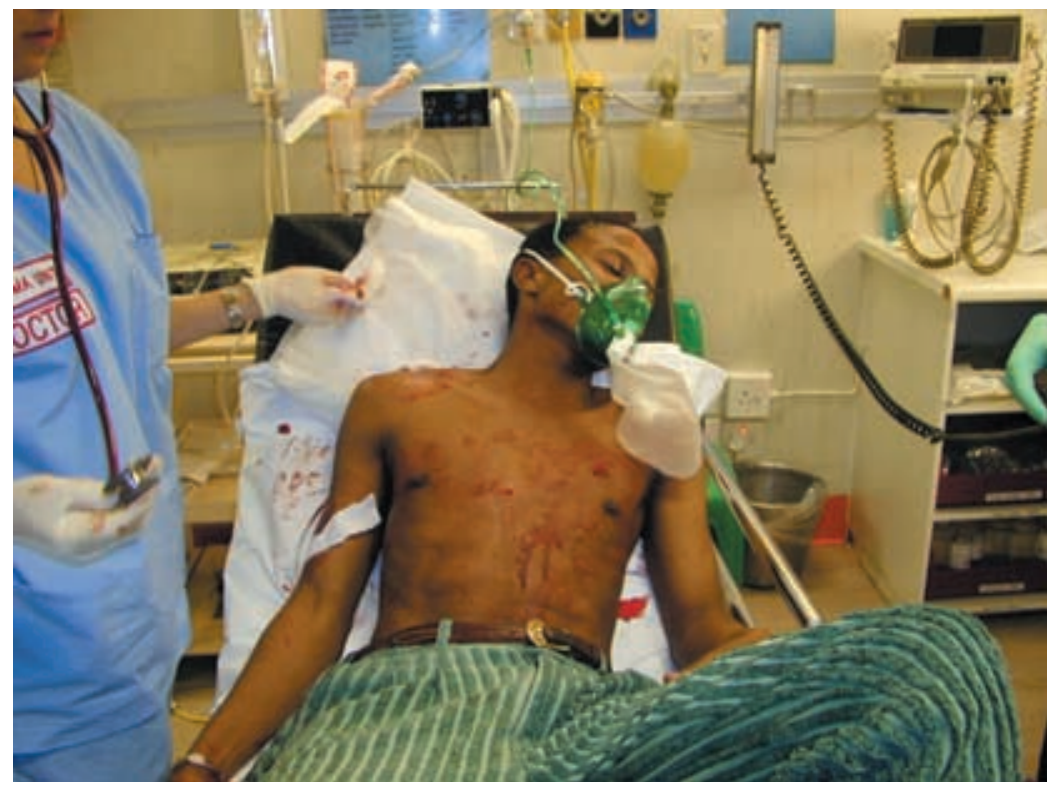

Fig 1. Two anterior chest stab wounds, one precordial, that missed all vital structures and did not even produce a pneumothorax. The patient was observed for 3 hours and discharged from the Trauma Unit. markers' on the skin at the sites of penetration before the patient is X-rayed. Paper clips on adhesive tape work very well, and give an indication as to the possible trajectory that the missile may have made through the body. This allows the resuscitation team to begin thinking about what potential internal damage to expect, and to anticipate what action may be required.

With the caveat about multiple cavity injury stated above, it is appropriate to view the torso regionally in this paper.

\section{Thoracic Injuries}

Thoracic injury is responsible for approximately 1 in 4 trauma related deaths in the USA, and is a significant contributing factor in another $25-70 \%$ of deaths due to traumatic multisystem injury (Powell et al 1998; Kirton 2000). It must be said that the majority of these will be due to motor vehicle accidents, and the proportion of those with penetrating trauma is difficult to tease out from the literature.

The dimensions of the thoracic cavity vary, being relatively small in expiration, when the diaphragm may reach the nipple line or 4 th intercostal space anteriorly, and the 7th space posteriorly. It is considerably larger in inspiration, where a deep breath can cause the diaphragm to descend as far as the 9th space anteriorly, the 10th space laterally, and the 12th rib posteriorly. This means that what may at first sight appear clearly to be either a thoracic or abdominal injury, may in fact turn out to be the opposite. It is safer to assume that both cavities have been breached if any doubt exists.

Similarly, penetrating wounds outside the chest - for example, Zone 1 in the neck - may well involve intrathoracic structures (Castellote et al 1999). This would require a different set of investigations, sometimes including angiography, if the patient's condition was sufficiently stable (Eddy 2000).

Penetrating wounds of the thorax will require urgent radiology of the chest, but this should never delay the diagnosis and treatment of a tension pneumothorax. A tracheal shift in a hypotensive patient with penetrating chest trauma should be regarded as a tension pneumothorax until proved otherwise - and acted upon (Wilson 1999). It should also be remembered that tracheal deviation is itself a late sign in tension pneumothorax.

Different series show that up to $85 \%$ of patients presenting with penetrating chest wounds may be treated by chest tube drainage alone, though it is worth noting that some will not need any form of drainage at all (Mattox et al 1996) (Figure 1). When drains are placed, it may be tempting to use the wound itself as the drain site - this should be resisted as the track the tube will follow 
will almost certainly be the path of the knife or bullet, and so is highly likely to precipitate further haemorrhage. A new incision should ALWAYS be made.

If there is a sucking wound, an Ascherman seal should be applied. It is safe to assume that those patients who have subcutaneous emphysema and require ventilatory support, will also need a chest drain - bilaterally, if there is mediastinal air and a possible transmediastinal injury. It is important to get a proper airtight seal around the tube. Various methods of suturing are available, of which mattress suturing is easiest and most effective. Purse string sutures should not be used. It is important to check that all the side holes in the chest tube are within the thorax or the continued air leak will not allow the lung to re-expand. Similarly, if there is a massive air leak despite proper placement of the tube, then a major bronchial injury must be suspected. This will almost certainly require operative intervention.

Although there is undoubtably a role for emergency room thoractomy in penetrating trauma, it is worth noting that ER thoracotomy for blunt trauma associated with the non-responding shocked patient is seldom accompanied by a successful outcome, and its use in the main trauma units in South Africa and many centres in the United States has been discontinued (Baker et al 1980; Rothenberg et al 1989; Jurkovitch et al 1992; Rhee et al 2000). It is also true to say that those who reach the ER who have had more than 5 minutes of pre-hospital cardiopulmonary resuscitation (CPR) unintubated, or more than 10 minutes of CPR intubated, almost invariably perish (Mattox 1989; Copass et al 1984; Rosemurgy et al 1993; Pasquale et al 1996).

Where possible, and after secondary survey, a chest X-ray should be taken in the sitting position because a moderate haemothorax of $500-1000 \mathrm{ml}$ of blood may be missed on supine films, especially if the patient is obese (Van Der Spuy et al 1991, Velmahos et al 1999). Furthermore, up to $50 \%$ of rib fractures may be missed on plain films, so it is better to assume the presence of fractures based on clinical signs and local tenderness rather than radiology, unless other forms of more sensitive imaging are immediately to hand (Chan et al, 1996; Bitshnau et al 1997).

The indications for thoracotomy are manifold and may be drawn from textbooks on trauma, but the most common indication is on-going exsanguinating haemorrhage. In the adult this is defined as more than $>1500 \mathrm{ml}$ draining immediately after insertion of the tube drain, or persistent draining of more than $>200 \mathrm{ml} /$ hour for more than 2-3 hours.

Peripheral lung lacerations are straightforward to treat in the majority of cases, needing simple oversewing or tractotomy with excision. The root of the lung is a wholly different matter, and these patients may well present 'bled out' and need ER thoracotomy in order to clamp the lung hilum. If it can be achieved, immediate transfer to the operating theatre for repair or resection is preferable to embarking on desperate measures (eg pneumonectomy) in the ER.

The surgical approach in the ER is a rapid, transverse, anterior thoracotomy on the affected side with the patient in the supine position, cutting as far posteriorly as the position of the patient will allow. If control of haemorrhage is obtained, then the incision can be extended further posteriorly in the operating theatre with the patient on his/her side to allow better access.

\section{Injuries to the Mediastinum}

The heart is probably the organ most likely to cause anxiety, and reasonably so. Survival for gun-shot wounds (GSWs) is significantly less $(\sim 15 \%)$ than for stab wounds $(\sim 70 \%)$. The mechanism of injury is therefore highly significant in determining survival, as is the presence or absence of sinus rhythm on opening the pericardium (Asensio et al 1998). The anatomical site of injury, in terms of the injured chamber, and the presence or absence of tamponade does not seem to have significant bearing on survival (Asensio et al 1998). Overall, approximately $75 \%$ of patients with penetrating cardiac wounds die before reaching hospital, and aortic injuries do particularly badly, with a pre-hospital mortality of over $90 \%$ (Demetriades et al 1983).

In cardiac tamponade, the decision to aspirate the pericardium remains controversial, but the consensus is that it is, at best, a holding procedure that buys time before a more definitive procedure. The technique's proponents will emphasise that as little as $5-10 \mathrm{ml}$ of blood aspirated may restore the patient's blood pressure. This seems questionable (Demetriades 1984; Demetriades 1986).

Whether needle aspiration is employed or a sub-xiphoid pericardial window created, is perhaps of less importance than suspecting the injury in the first place. All patients in shock with penetrating chest wounds between the mid-clavicular line on the right and the anterior axillary line on the left should be considered to have a cardiac injury until proved otherwise.

Classic eponymous syndromes may be of help, but should not be thought of as essential to the diagnosis. For example, the physical signs of Beck's Triad (distended neck veins, hypotension and muffled heart sounds,) may not be present, as the heart sounds may still be clearly audible, even with more than $100 \mathrm{ml}$ of blood in the pericardium. Indeed, this triad may be falsely negative or positive in up to one third 


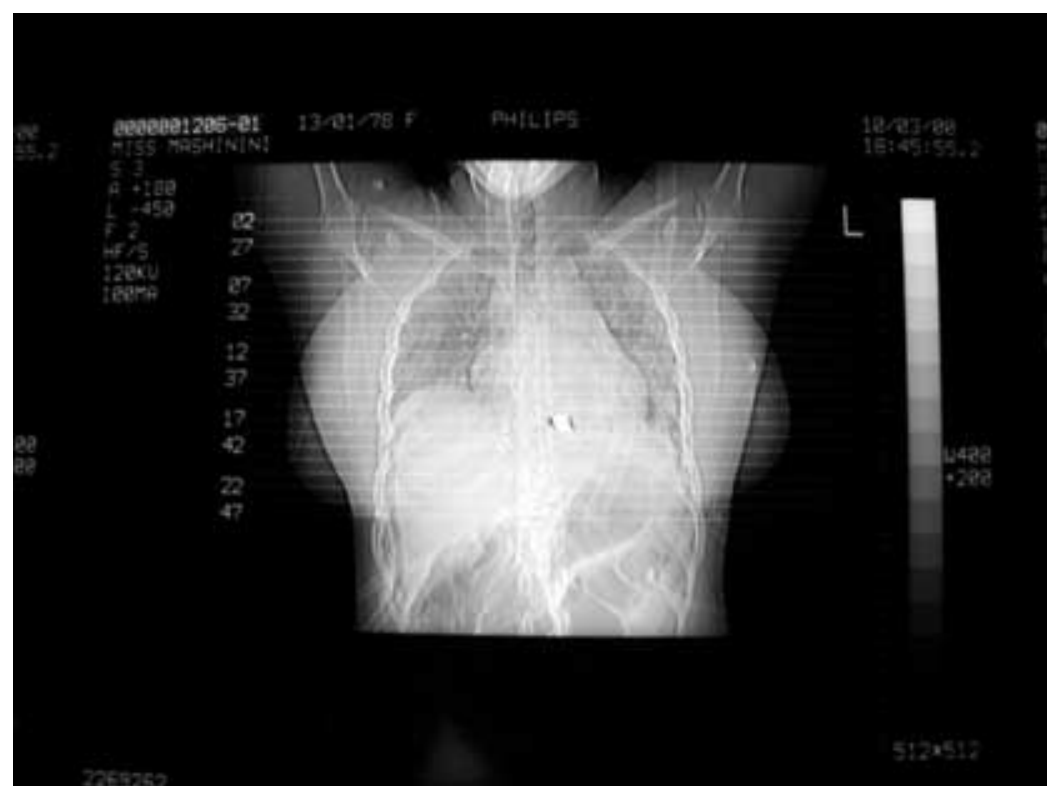

Fig 2. GSW to right flank. Bullet embolised from IVC to the right ventricle. Preliminary CT scan shows the bright image of the round in the heart. No breach of the chest cavity.

of cases (Wilson 1999), especially when the patient is being examined in a noisy environment.

Distended neck veins can be caused by a number of mechanisms other than cardiac tamponade. Breathing abnormally or straining may produce this physical sign, and tension pneumothorax, mediastinal haematoma, heart failure, or air emboli can also raise the CVP and lower the blood pressure.

Emergency Room (ER) thoracotomy for cardiac injuries carries a mortality rate of 85 $95 \%$, compared with a $10-15 \%$ mortality if the patient can survive to have surgery in the operating theatre where the definitive procedure is best done through a median sternotomy (Asensio et al 1998).

The posterior mediastinal structures are not easily reached through a median sternotomy, and would be better approached by a posterolateral thoracotomy if the patient is stable, or an anterolateral thoracotomy for the unstable patient.

If the posterior mediastinal structures have been injured, especially the tracheobronchial tree, then the acquisition of a definitive airway may be extremely challenging. It may require cricothyroidotomy if there is significant facial trauma (where nasotracheal intubation would be contraindicated), or, if there is suspected tracheal disruption, transnasal or transoral fibreoptic intubation under direct vision.

In summary, if there is evidence of a transmediastinal injury, and the patient is dying in front of one's eyes, the chest should be opened in a bilateral 'clam-shell' anterolateral thoracotomy. If more time is available the patient should be transferred to the operating theatre for assessment via a pericardial window followed by median sternotomy. In the stable patient, investigations should be carried out by one or more of the following methods:aortography, bronchoscopy and Barium swallow and/or 'scope. None of these investigations is any more than $60 \%$ diagnostic on its own, but in combination they may achieve $90 \%$ accuracy. Injury to the great vessels may require extension of the sternotomy upwards into the neck (on either side) to expose the subclavian and carotid vessels.

It is important to remember that bullets and missiles - and indeed knives - may be deflected from penetration of the thoracic cavity by the ribs, and what may seem to be a 'through and through' wound, may simply have followed the rib around from one side of the body to another. In this way, an 'entry' wound in the right anterior chest may end up exiting (or remaining subcutaneous) in the paravertebral muscles or skin of the back, not actually having traversed the thoracic cavity at all.

In the same way, missiles may end up in the most unlikely of places through vascular embolisation, producing bizarre symptoms. Arterial embolisation from a GSW to the chest has been reported as causing acute lower limb ischaemia. The round had entered the thoracic aorta and travelled to the right external iliac artery where it lodged. In another case, a GSW to the right flank, the bullet was found in the right ventricle, having embolised through the IVC up into the right atrium and thence to the ventricle. An uneventful extraction ensued with a successful result (personal case.) The message is to be prepared for the unexpected! (Figure 2).

\section{Abdominal Injuries}

As penetrating wounds of the thorax can produce bizarre patterns of injury, so, in the words of Sir Zachary Cope, is the abdomen 'a temple of surprises'. The great challenge of the abdominal penetrating injury is not to miss one!

The abdomen is often opened in haste to save a patient from catastrophic haemorrhage from the liver or other major structure, and a hole in the diaphragm, or tangential wound to the transverse colon or pancreas, is missed - because it is not sought, or is overlooked as apparently insignificant. These injuries may still be fatal.

The ATLS dictum of 'fingers and tubes in every orifice' is essential, and the measurement of core temperature by a rectal thermometer must not be forgotten. The lethal combination of acidosis, hypothermia and coagulopathy needs to be prevented at all costs (Seekamp et al 1995; Genetillello et al 1997), and rectal temperature, measured as part of the secondary survey, may give advance warning that a patient is already on a downward slope, when nothing more than 'damage control' surgery should be considered. 
There is a move towards conservative management in penetrating abdominal injuries as a result of the high negative laparotomy rates encountered between 1900 and 1960 . In the early 1900 s, the surgeon relied on history and examination alone, with the consequence that up to $45 \%$ of intraperitoneal injuries were missed. In response to this, the pendulum swung too far the other way, and increasing numbers of laparotomies revealed no reparable pathology. More advanced investigative techniques were used to try to stem the tide of unnecessary surgery.

Diagnostic Peritoneal Lavage (DPL) was first advocated in 1965 for blunt abdominal injury, and this was subsequently extended to include penetrating injury (Boone et al 1998). DPL in blunt abdominal trauma is probably of more value than in penetrating trauma as the sensitivity is higher in the latter, resulting in a higher negative laparotomy rate (Wilson 1999). Actual values for a positive DPL are generally agreed to be an RBC count $>100,000 / \mathrm{mm}^{3}$ for blunt trauma, but less agreement is found over the value for penetrating trauma. Different sources quote RBC counts from $>1,000 / \mathrm{mm}^{3}$ to $>100,000 / \mathrm{mm}^{3}$ to reflect a positive test, but average out at $>10,000 / \mathrm{mm}^{3}$. If the major concern is whether a penetrating chest wound has punctured the diaphragm, then the lower figure of $\mathrm{RBC}>1,000 / \mathrm{mm}^{3}$ can be regarded as positive (Petersen et al 1979).

Clinicians came to realise that the presence of blood in the peritoneal cavity could not necessarily be related to the need for laparotomy, but that the test, viewed in conjunction with the physical state of the patient, could help to build up a picture of the overall pathology.

Computerised Tomography (CT) has replaced or enhanced the value of DPL (particularly in blunt trauma) in some centres since the early 80 s, often with the use of

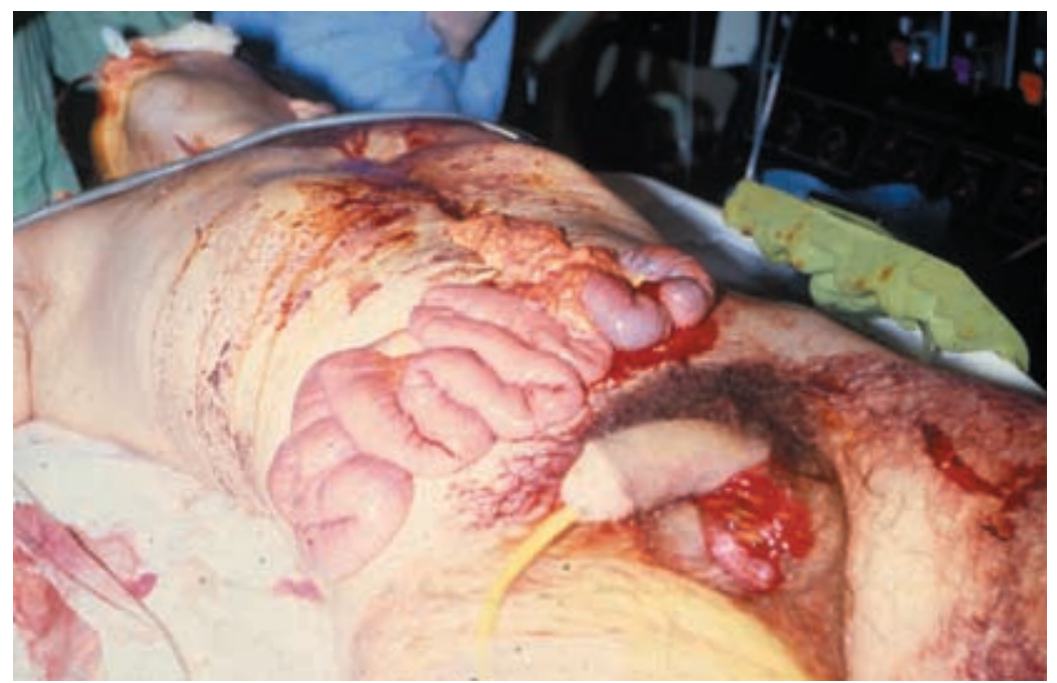

Fig 3. Self-inflicted injury. Multiple lacerations and stab wounds with intent (partially successful!) to disembowel. Left common iliac artery and right common iliac vein both lacerated. Haemorrhage contained by retroperitoneal haematoma.

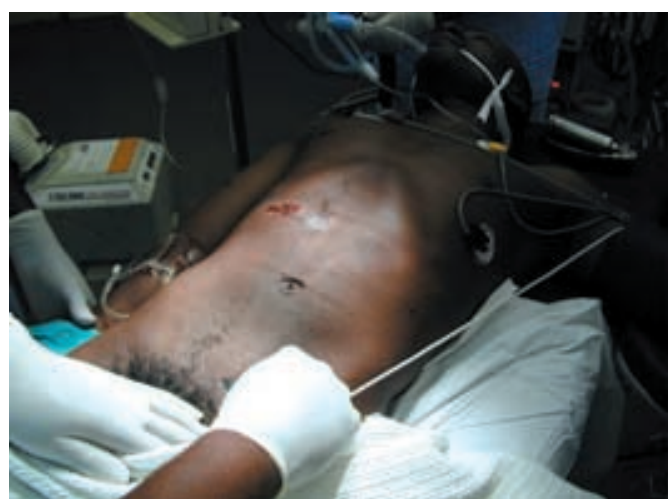

Fig 4. GSW of right upper quadrant. Injuries to liver, colon, gallbladder, small bowel, and Gerota's fascia surrounding the upper pole of the right kidney. No renal parenchymal damage.

double (oral) or even triple (rectal) contrast used with the standard intravenous contrast. CT is, of course, absolutely contraindicated in haemodynamically unstable patients.

Algorithms abound in the handbooks on abdominal trauma but in the end, it is often safer to look than to wonder, and to accept a negative laparotomy rate of around $20 \%$. ER ultrasound, DPL, CT, and even (in some centres) diagnostic laparoscopy (DL) are all in use, and all have their heralds of triumph and prophets of doom. Most often the local policy is dictated by the expertise of one or other enthusiast of a particular technique.

Ultimately, there is little contention over the need for immediate laparotomy in the unstable patient with a distended abdomen or evisceration. (Figure 3). It is important to realise that in torso trauma - and in the abdomen perhaps more than the chest - the potential outcome is considerably influenced by which organs are affected. (Figure 4 ).

A knife wound may seem innocuous indeed, it may have barely penetrated the peritoneal cavity - but it may have punctured the abdominal aorta, especially in the slim individual. In Figure 3, both the right common iliac artery and left common iliac vein had been breached where the former crosses the latter, and the haemorrhage was contained only by a sizeable retroperitoneal haematoma. Thus, the size of the entry wound bares no relation to the amount of damage that may have been caused. However, it is estimated that up to $25 \%$ of stab wounds fail to penetrate the peritoneal cavity, and in the stable patient there is a place for local wound exploration (LWE) under local anaesthetic in the ER. If a breach in the deep fascia or peritoneum is found particularly if this is combined with a positive DPL, then exploration is appropriate.

In GSWs, the damage caused is related not only to the velocity of the missile, which determines the potential energy transfer into the tissues in its path, but also the nature of the tissue that it traverses. Solid organs, like the liver, kidneys and spleen, are more liable to massive disruption with high energy rounds than air containing organs such as the 
lungs or gut. The velocity of the round and the tissue it strikes are important, but the amount of destruction caused is also determined by the attitude of the round as it strikes the body, and its behaviour subsequently as it passes through different tissues (Cooper 1990). Does the round have a regular profile? Does it spin, tumble or yaw? Does it fragment on impact? All these issues have significant bearing on the degree of internal mayhem that may be found.

Some clues may be gained from radiographs, particularly when a projectile fragments, though it is not necessary to hunt down and remove every last piece of metal. Indeed, experience has shown in limb injury that the majority of fragments may safely be left (Bowyer 1996; Demetriades et al 1993), and other experimental work has demonstrated that projectiles traversing the colon do not take large amounts of contamination with them. It is, therefore, better not to explore paravertebral muscles where a bullet may have lodged, as this will cause more unnecessary tissue damage (Edwards et al 1999; Sarmiento et al 1997), though not all would agree with this policy (Coburn et al 1995).

Even when clearly demonstrable damage has occurred to major structures, there may still not be a need to operate if the patient is stable. Recent papers have described the conservative management of GSWs to the liver, spleen and kidney, where capsular haematomata confine the damage and show no signs of expansion, and where the patient shows no signs of deterioration (Demetriades et al 1999; MacFarlane 1999). (Figure 5)

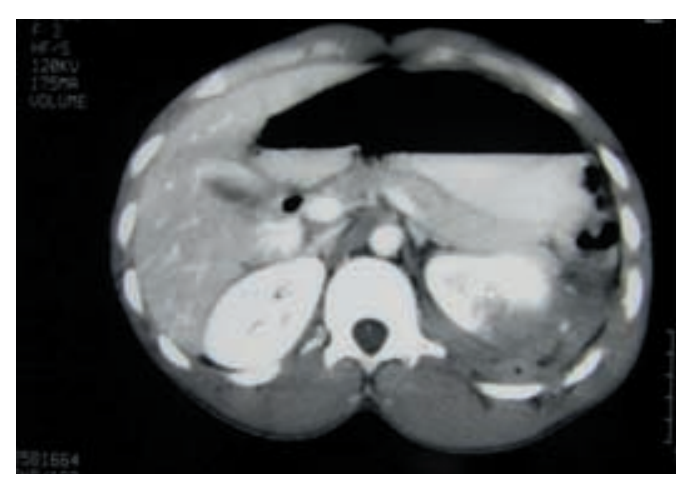

Fig 5. CT scan showing track of bullet passing through the spleen and left kidney. It fractured the spinous process of the 2nd lumbar vertebra and exited to the right of the midline in the subcutaneous tissues of the back. Conservative management only was undertaken as the patient was stable at all times. The patient was discharged after 48 hours observation.

The Johannesburg experience of gunshot wounds found that no single investigation could determine the need for laparotomy, and that the most reliable decision making was achieved by repeated physical examination by an experienced clinician (Rotondo et al 1993).

\section{Surgical Considerations}

It is highly likely that penetrating wounds of the peritoneal cavity will have breached the integrity of the intestine, and antibiotics should be given. They should provide both aerobic and anaerobic cover. Numerous choices exist, but Co-amoxyclav (Augmentin $($ ), as a single agent, saves using combinations of drugs and has the required spectrum of activity. The antibiotics should be given intravenously, ideally within 2 hours of injury, and consideration should be given to early repeated doses, especially where there is significant continuing blood loss.

There is little doubt that the fastest way into the abdomen is by a long midline incision. This has the advantage that it not only provides access to both sides of the abdominal cavity, but is rapidly extendable into the chest by sternotomy, if required. However, there are occasions when the patient comes into the ER in extremis, with a distended gunshot abdomen and sustained hypotension ( $<70 \mathrm{~mm} \mathrm{Hg}$ ), and heroic measures are justified. This necessitates a rapid left antero-lateral thoracotomy, cutting as far posteriorly as possible, to place a crossclamp on the descending thoracic aorta. This should attenuate the intra-abdominal blood loss, and allow rapid transfer to the operating theatre.

There should be an operative protocol that is strictly adhered to. Two high volume suction devices should be working before the abdominal cavity is opened.

The aim of the operation is control of haemorrhage and contamination. How much more can be achieved depends on the condition of the patient and the experience of the surgeon. It is not within the remit of this article to attempt to detail the treatment of any of the myriad injuries that may be encountered on opening the abdomen.

The abdomen should be packed as soon as it is opened. There is no place for trying to 'have a look' for the damage until some control over the blood loss and soiling has been achieved. Firm, four-quadrant packing should rapidly allow the operator to determine where the most damage has occurred.

\section{Haemorrhage}

Almost certainly the most challenging solid organ injury is the shattered liver (Marr et al 2000). Packing of the liver to control bleeding is not done by pushing large swabs desperately into the lacerations. This will widen them and make the haemorrhage worse. Solid organs are packed so that the pieces are kept together, and compressed. This can require fine judgement, as packing too tight will produce necrosis, but it is better to err on that side if the alternative is an exsanguinated patient. Whether swabs are opened out or folded is largely a matter of personal taste, but the author's preference is 
for folded swabs as they are easier to insert and produce a more even pressure.

Where possible repair is undertaken, if time allows, but it may be more expedient to remove part or all of a severely damaged kidney or spleen, and surprisingly large amounts of liver can be excised with a successful outcome.

Major vessel injury is controlled by direct pressure with a fist or large mounted swab while proximal and distal access for definitive control is sought. If the surgeon has limited vascular expertise, and none is readily available, then temporary clamping or intraluminal shunting may give time to get the patient to a facility where the relevant expertise is on hand. Caution should be exercised in this endeavour, as the inferior vena cava and iliac veins do not take rough handling, and clamps will often tear these major veins and make bleeding worse. It may be better to firmly pack such structures. Arteries withstand clamping much better, being thicker walled.

\section{Contamination}

Isolating holes in the gut is usually best done by soft clamping of the affected segment(s), and wrapping with a Betadine $\AA$ soaked swab - or equivalent. Holes found close together, if small, may be expeditiously 'joined' to form one larger perforation by cutting the bridge of tissue between them. This can make subsequent closure much easier. Clearly, if there is significant damage to the mesentery, or multiple perforations have largely macerated a section of gut, then resection is indicated. Classical teaching would advise no anastomosis - especially in the large bowel - necessitating colostomy.

Nonetheless, it is important to know that recent research has questioned the traditional wisdom of always exteriorising colonic wounds. Work performed within DERA and validated in clinical practice has shown that the large majority of simple colonic wounds may be closed primarily without diversion, with the proviso stated above concerning major damage and contamination (Edwards et al 1999). Small bowel wounds have been primarily closed safely for many years. Skin staples have made the closure of bowel injuries increasingly swift without additional morbidity (Howell et al 1991).

\section{Damage Control}

The concept of 'damage control' surgery has been alluded to earlier in this article. It applies to the injury of all parts of the body, but perhaps none more so than the abdomen with extensive visceral injuries (Hirshberg et al 1995; Burch et al 1992, Rotondo 1998).

A $\mathrm{pH}<7.30$, a core temperature $<35^{\circ} \mathrm{C}$, and a coagulopathy are a lethal combination, and are indications to stop operating, providing haemorrhage control has been effected. If on-going haemorrhage is not arrested, then a fatal outcome will still occur no matter how enthusiastic the packing of the abdomen. The coagulopathy can be suspected - by the transfusion of $>10$ units of blood (packed cells), tested for - by the findings of elevated INR, APPT and thrombocytopaenia, or visualised - by the appearance of non-mechanical bleeding in the operative field. If, in addition to all of the above, the total time for resuscitation and operation have already exceeded 90 minutes, then the chances for survival are very much reduced (Rotondo 1998).

If the above vicious cycle is to be broken before it claims the life of the patient, then rapid attenuation of the surgical procedure must follow, with transfer of the patient to an Intensive Care Unit. To this end, vascular repairs may be deferred by intraluminal shunting or firm packing, (with the caveat mentioned in the preceding paragraph) and diversion of intestinal contents is performed rather than lengthy resection of bowel. Indeed, bowel ends may be simply tied off with tapes to prevent further contamination if time does not allow for stoma formation. The abdomen should be left open, but covered with some occlusive membrane such as OpSite ${ }^{\circledR}$ wrapped around large abdominal packs and placed in the laparotomy - the so-called Johannesburg 'Op-Site Sandwich'. Even an intravenous fluid bag, empty, and cut open into a rectangle, will suffice if rapidly stitched or clipped to the skin.

In the Intensive Care Unit the patient is rewarmed, the acidosis corrected, and the coagulopathy addressed. Planned secondlook surgery may then be scheduled once the patient's physiology has been normalised. Definitive procedures at second-look may more appropriately be done after transfer to another surgical facility with more experience in the management of penetrating trauma.

\section{Abdominal Compartment Syndrome (ACS)}

This condition is brought about by rising intra-abdominal pressure (IAP), usually as a result of too tight an abdominal closure or swelling of the gut, and often made worse by the contribution of over-enthusiastic intravenous fluid administration in the resuscitative phase. This fluid then sequestrates in the gut wall and retroperitoneum, effectively reducing the capacity of the abdominal cavity.

Clinically, the condition is manifest by a need to increase the ventilator peak inspiratory pressure and the positive endexpiratory pressure (PEEP) in order to oxygenate the patient. There is decreased compliance as the diaphragm is raised due to the increased IAP. The cardiac output drops, the central venous pressure increases, the renal function decreases, urine output drops and abdominal girth increases (Schein et al 1995). 
Some estimate of the intra-abdominal pressure needs to be made, and intra-vesical pressure is taken as equivalent to, or reflecting IAP, and can be monitored easily through an indwelling Foley catheter and a Y-connector. Details of this procedure and other methods of assessing IAP can be found in the literature. IAPs $>25 \mathrm{~mm} \mathrm{Hg}\left(25 \mathrm{~cm} \mathrm{H}_{2} \mathrm{O}\right)$ should prompt rapid re-opening of the abdomen, on the Intensive Care Unit if necessary, if a 'second-hit' phenomenon of splanchnic hypoperfusion, acute tubular necrosis (ATN), and multiple organ failure are not to follow swiftly in the wake of established Abdominal Compartment Syndrome.

\section{Some problem areas}

The retroperitoneum presents many diagnostic challenges. Whether to explore at all is as much a problem as when. It is usually safe to say that if the abdomen has to be opened, then the retroperitoneum above the pelvic brim should be exposed and declared free of injury before closure.

It is essential that all surgical manoeuvres to expose the retroperitoneal structures should be familiar to the surgeon, including extended Kocher's procedures from both the right and the left. Access to the lesser sac and mobilisation of the pancreas should also be within the technical armamentarium of the operator.

In this way, it should be possible for the kidneys, duodenum, pancreas and great vessels to be exposed. Vascular surgical experience is one of the most useful attributes that a surgeon can bring to the management of trauma, and injuries to the aorta and IVC can concentrate the mind wonderfully. Strategies for initial control have been outlined earlier.

Techniques of hepatic isolation and IVC

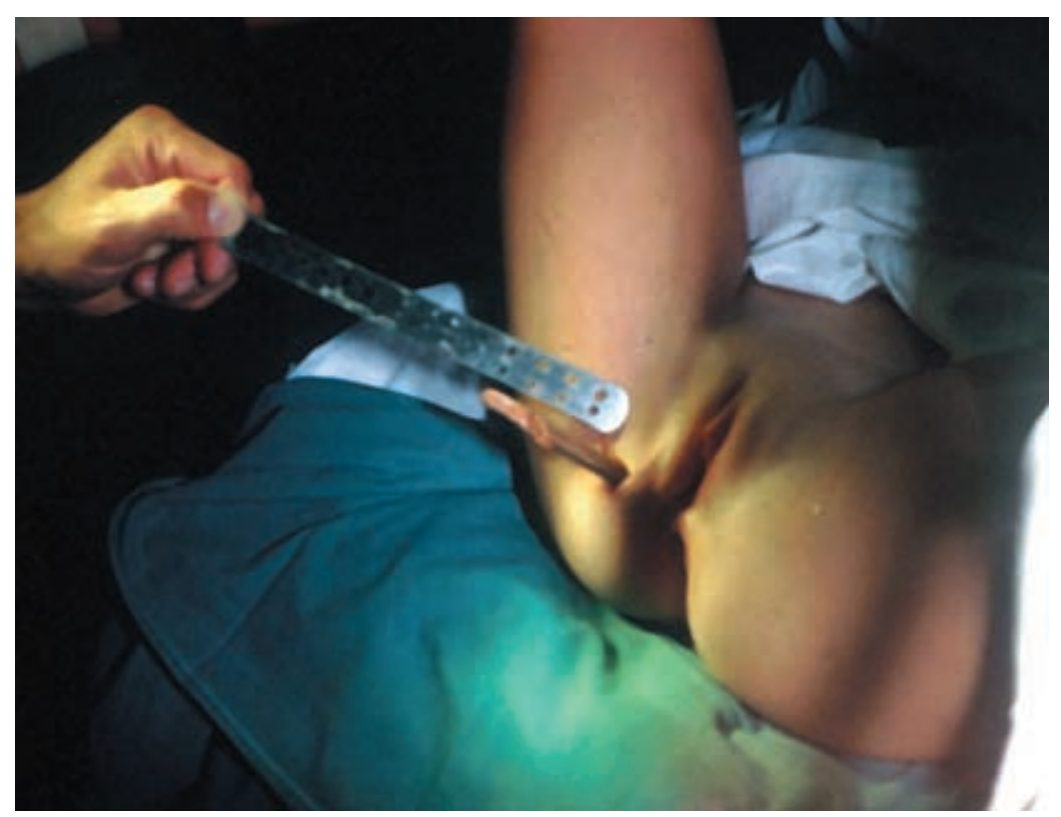

Fig 6. Penetrating wound of the perineum. A wooden chair collapsed beneath her and she was impaled on one of the cross-struts. Rectal injury, vaginal injury and sciatic nerve neuropraxia. Diverting colostomy, and vaginal repair. Uneventful recovery. Stoma closed at 12 weeks. shunting for retrohepatic caval injury, either inside or out of the pericardium, are not within the scope of this article, and are best obtained by hands-on experience, as well as by reading the relevant texts. Nonetheless, the Pringle manoeuvre of clamping the free edge of the lesser omentum to occlude the portal triad should be within the grasp of all. The best that may be achievable whilst awaiting the vascular/trauma surgeon, is to pack the liver pieces together, hard back against the cava, having mobilised it from its attachments to the diaphragm. The infrahepatic cava may be compressed sideways against the vertebral column to buy time and allow the anaesthetist to catch up with blood loss. Posterior holes in the IVC may sometimes be most easily approached from the front, exposing the posterior wall through an anterior incision into the cava. This may be safer than trying to rotate it between clamps, where tearing of lumbar veins will only compound the injury, but neither of these manoeuvres is for the beginner. Although, in the moribund patient, the cava may be ligated, this may not be easy if visibility and access are poor.

\section{The Pelvis}

Pelvic penetrating injury can be spectacular in its inaccessibility. The young, slim male may seem an ideal operative candidate but there is often inadequate space within the pelvic aperature to place two average hands for the surgery, along with his damaged organs. At the opposite end of the spectrum, the obese female, whilst having a capacious pelvic brim, may have huge amounts of intraperitoneal fat draped over her pelvic colon, obscuring everything in its way, and tempting the surgeon to embark on illadvised resections for improved visibility.

Nevertheless, the expanding pelvic haematoma is the area where most caution is advised. Pelvic veins hide behind structures of importance: the rectum, the ureters and the iliac arteries. Pelvic veins are thin-walled and do not take sutures, or tolerate diathermy well.

The portals of entry into the pelvic cavity are protean and often imaginative, testing the diagnostic capabilities of the surgical team. The butcher's knife injury in the groin that slices upward to injure the bladder and bowel, along with the iliac vessels is well recognised. Perhaps less well remembered is the entrance through the perineum or sciatic notch. (Figure 6). Some more unpleasant gang-land 'punishments' include forced impaling through the vaginal vault or rectum, where no external sign of injury may be apparent.

It is essential that a thorough examination is made of the perineum, vulva, and vagina - in addition to the rectum. In the case of assault or rape, not only may injuries be missed, but also vital forensic evidence may be destroyed 
by the misplaced modesty of the clinician, or the shame, upset and anxiety of the patient. It may be necessary to perform these examinations under general anaesthetic.

Occasionally, the trauma victim will be found to be pregnant. The finding of a pregnancy will add to the diagnostic, ethical, and surgical challenges facing the trauma team. It is salutary to note that maternal death is the most common cause of foetal death after trauma, as it is often assumed that the foetus is more susceptible to injury (Udekwu et al 1998). After 26 weeks the foetus is viable, and it may be necessary to perform a rapid Caesarean section to save the baby in a moribund mother - or to gain access to the site of pelvic injury in the mother.

Rectal injuries, if full thickness, should be treated by diversion. This may be in the form of a sigmoid loop colostomy and pre-sacral drainage, but both of these procedures have been questioned. A more certain method of definitive faecal diversion is to perform an end colostomy and mucous fistula, a Hartmann's resection with oversewing of the rectal stump, or a loop colostomy with stapling of the distal end. In any of these options, an anal stretch to render the anal sphincter temporarily incontinent of flatus, will reduce the possibility of pressure buildup within the rectal stump and potential blow-out.

\section{Military Applications}

It must be appreciated that the descriptions outlined in the article above assume that modern imaging facilities are available and that there is instant access to a well-equipped operating theatre. In a theatre of war, the picture may be very different.

The principles of casualty handling in an operational setting depend upon the safety of those already injured from further harm, the safety of those who would seek to help them, the proximity of a reasonable surgical facility, and the equipment and experience of those in that facility. There will be constraints on the number of procedures that can be done as much a result of limited equipment and the ability to re-sterilise it, as by the energy and sustainability of the staff attending to the injured.

Consideration should also be given to the likelihood of receiving overwhelming numbers of casualties, when the rigorous application of triage to obtain the greatest good for the greatest number will be essential, even if harrowing in its execution. In the scenario of battlefield or maritime conflict, people will die, when they might not have if they had been in a well-equipped modern hospital with personnel experienced in the management of penetrating injuries. This has huge implications and emphasises the imperative to train military personnel to the highest standard in the management of penetrating injuries of all descriptions.

Further differences to be anticipated are that wounds may well be multiple, and some, at least, may be the result of high energy missiles. The latter casualties will rapidly die if a solid organ such as the liver is traversed and immediate surgical intervention is not to hand, so those surviving to reach a surgical facility have self-selected, and should be treated according to the principles outlined in the main body of the paper. It is important to bear in mind, however, that the cavitation effect of a high-energy round causes much more destruction of tissue than that of its lower energy counterpart.

Finally, it should not be forgotten that battlefields and battleships are dirty places and this should raise the banner of caution when operating on the injured. Contamination from the outside is as likely as from the inside, and wounds should not usually be primarily closed - with the exception of the chest, for the maintenance of intrathoracic integrity and other selected sites where primary closure is permissible, for example, the face. Delayed primary suture of the wound is a lesson that, sadly, continues to need to be re-learned in every new conflict, at a high cost to patients' morbidity and mortality. The axiom - close the cavity (if appropriate), but leave the wound open - is still valid.

\section{Conclusions}

Penetrating injuries of the torso are not as common as wounds of the extremities - in war at least - though in the context of urban interpersonal violence, most injuries are inflicted at close range, and have a greater tendency to involve the torso. As such, they are likely to be more demanding in their scope, diagnostic challenge, and potential severity than isolated limb injuries. The possibility of multiple cavity injury should never be forgotten and a systematic approach is essential. In the critical patient, damage control surgery offers a rational life saving approach for early management.

\section{References}

Asensio JA, Berne JD, Demetriades D, et al. One hundred five penetrating cardiac injuries: a 2-year prospective evaluation. F Trauma 1998; 44 (6): 1073-82. Asensio JA, Murray J, Demetriades D, et al. Penetrating cardiac injuries: a prospective study of variables predicting outcomes. F Am Coll Surg 1998; 186 (1): 2434.

Baker CC, Thomas AN, Trunkey DD. The role of emergency room thoracotomy in trauma. $f$ Trauma 1980; 20 (10): 848-55

Bernado LM, Henker R, Bove M, Sereika S. The effect of administered crystalloid fluid temperature on aural temperature of moderately and severely injured children. F Emerg Nursing 1997; 23 (2): 105-11.

Bishop MH, Shoemaker WC, Appel PL, et al. Prospective, randomized trial of survivor values of cardiac index, oxygen delivery, and oxygen consumption as resuscitation endpoints in severe trauma. F Trauma 1995; 38 (5): 780-7. 
Bishop MH, Shoemaker WC, Appel PL, et al. Relationship between supranormal circulatory values, time delays, and outcome in severely traumatized patients. Crit Care Med 1993; 21 (1): 56-63.

Bitschnau R, Gehmacher O, Kopf A, Scheier M, Mathis G. [Ultrasound diagnosis of rib and sternum fractures] [German]. Ultraschall in der Medizin 1997; 18 (4): 15861.

Boone DC, PeitzmanAB. Abdominal injury. In: The Trauma Manual. 1998. Eds. Peitzman AB, Rhodes M, Schwab CW, Yealy DM. Lippincott-Raven. Ch 26; 226264.

Bowyer GW. Management of small fragment wounds: experience from the Afghan border. F Trauma 1996; 40 (3 Suppl): S 170-2.

Burch JM, Ortiz VB, Richardson RJ, et al. Abbreviated laparotomy and planned reoperation for critically injured patients. Ann Surg 1992; 215: 476.

Cairns CB, Moore FA, Haenel JB, Ortner JP, Rose SJ, Moore EE. Evidence for early supply independent mitochondrial dysfunction in patients developing multiple organ failure after trauma. F Trauma 1997; 42 (3): 532-6.

Castellote A, Vazquez E, Vera J. Cervicothoracic lesions in infants and children. Radiographics 1999; 19(3): 583-600. Chan O, Hiorns M. Chest trauma. (Review). Euro ff Radiology 1996; 23 (1): 23-24.

Coburn MC, Pfeifer PJ, Deluca FG. Nonoperative management of splenic and hepatic trauma in the multiply injured pediatric and adolescent patient. Arch Surg 1995; 130 (3): 332-8.

Cooper GJ, Ryan JM. Interaction of penetrating missiles with tissues: some common misapprehensions and implications for wound management. $\mathrm{Br} \mathcal{F}$ Surg 1990; 77: 606-10.

Copass MK, Oreskovich MR, Bladergroen MR. Prehospital cardiopulmonary resuscitation of the critically injured patient. Am F Surg 1984; 148: 20. Demetriades D. Cardiac wounds. Experience with 70 patients. Ann Surg 1986; 203 (3): 315-7.

Demetriades D, Charalambides D. Gunshot wounds of the colon: role of retained bullets in sepsis. Br $\mathcal{F}$ Surg 1993; 80 (6): 772-3.

Demetriades D, Gomez H, Chahwan S, Charalambides $\mathrm{K}$, et al. Gunshot injuries to the liver. The role of selective nonoperative management. I Am Coll Surg 1999; 188: 343-8.

Demetriades D, Van Der Veen BW. Penetrating injuries of the heart: experience over two years in South Africa. F Trauma 1983; 23 (12): 1034-41.

Demetriades D. Cardiac penetrating injuries: personal experience of 45 cases. Br 7 Surg 1984; 71 (2): 95-7. Durham RM, Neunaaber K, Mazuski JE, Shapiro Mj, Baue AE. The use of oxygen consumption and delivery as endpoints for resuscitation in critically ill patients. $\mathcal{F}$ Trauma 1996; 41 (1): 32-40.

Eddy VA. Is routine arteriography mandatory for penetrating injury to zone 1 of the neck? FTrauma 2000; 48 (2): 208-14.

Edwards DP, Brown D, Watkins PE. Should colonpenetrating small missiles be removed? An experimental study of retrocolic wound tracks. F Invest Surg 1999; 12 (1): 25-9.

Edwards DP, Warren BF, Galbraith KA, Warkins PE. Comparison of two closure techniques for the repair of experimental colonic perforations. Br F Surg 1999; 86 (4): 514-7.

Genetilello LM, Jurkovich GJ. Stark MS, Hassantash SA, O'Keeke GE. Is hypothermia in the victim of major trauma protective or harmful? A randomized, prospective study. Ann Surg 1997; 226 (4): 439-47. Hirshberg A, Mattox KL. Planned reoperation for severe trauma. Ann Surg 1995; 222 (1): 3-8.

Howell GP, Ryan JM, Morgans BT, Cooper GJ. Assessment of the use of disposable skin staplers in bowel anastomoses to reduce laparotomy time in penetrating ballistic injury to the abdomen. Ann Roy Coll Surg Eng 1991; 73 (2): 87-90.

In: Advanced Trauma Life Support - Student Manual, 1993. Am Coll Surg pp11-12.

Jurkovich GJ, Greiser WB, Luterman A, Curreri PW. Hypothermia in trauma victims: an ominous predictor of survival. F Trauma 1987; 27 (9): 1019-24.

Jurkovich GJ, Esposito TJ, Maier RV, Resuscitative thoracotomy performed in the operating room. $A m \mathcal{F}$ Surg 1992; 163 (5): 463-8.

Kincaid EH, Miller PR, Meredith JW, Rahman N, Chang MC. Elevated arterial base deficit in trauma patients: a marker of impaired oxygen utilisation. $7 \mathrm{Am}$ Coll Surg 1998; 187 (4): 384-92.

Kirton OC. Blunt thoracic trauma. In: Manual of Trauma and Emergency Surgery. 2000. Eds. Shatz DV, Kirton OC, McKenney MG, Civetta JM. WB Saunders Company. Ch 7; 82-93.

MacFarlane C. Management of gunshot wounds: the Johannesburg experience. International Surgery 1999; 84 (2): 93-8.

Marr JDF, Krige JEJ, Terblanche J. Analysis of 153 gunshot wounds of the liver. Brit F Surg 2000; 87: 1030 34.

Mattox KL, Wall MJ, Pickard LR. Thoracic trauma: general considerations and indications for thoracotomy. In: Trauma, 3rd ed., 1996. Eds. Feliciano DV, Moore EE, Mattox KL. Stamford, Appleton \& Lange. Ch 22 345-353.

Mattox KL. Prehospital care of the patient with an injured chest. Surg Clin North Am 1989; 69: 21.

Mitchell KJ, Moncure KE, Onyeije C, Rao MS, Siram

$\mathrm{S}$. Evaluation of massive volume replacement in the penetrating trauma patient. Nat Med Ass 1994; 86 (12): 926-9.

Pasquale MD, Rhodes M, Cipolle MD, Hanley T, Wasser T. Defining "dead on arrival": impact on a level 1 trauma center. F Trauma 1996; 41 (4): 726-30.

Petersen FR, Sheldon GF. Morbidity of a negative finding at laparotomy in abdominal trauma. Surg Gynecol Obstet 1979; 148: 23.

Powell MA, McMahon D, Peitzman AB. Thoracic injury. In: The Trauma Manual. 1998. Eds. Peitzman AB, Rhodes M, Schwab CW, Yealy DM. LippincottRaven. Ch 25; 199-225.

Rhee PM, Acosta J, Wang D, Jordan M, Rich N.Survival after emergency department thoracotomy : review of published data from the past 25 years. F Am Coll Surg 2000; 190 (3): $288-98$

Rhodes M. Trauma Resuscitation. In: The Trauma Manual. 1998. Eds. Peitzman AB, Rhodes M, Schwab CW, Yealy DM. Lippincott-Raven. Ch 13; 82-90.

Root HD, Houser CW, MCKinley CR, et al. Diagnostic peritoneal lavage. Surgery 1965; 57: 633.

Rosemurgy AS, Norris PA, Olson SM, Hurst JM, Albrink MH. Prehospital traumatic cardiac arrest: the cost of futility. F Trauma 1993; 35 (3): 468-74.

Rothenberg SS, Moore EE, Moore FA, Baxter BT, Moore JB, Cleveland HC. Emergency Department thoracotomy in children - a critical analysis. F Trauma 1989; 29 (10): 1322-5.

Rutherford EJ, Fusco MA, Nunn CR, Bass JG, Eddy

VA, Morris JA Jr. Hypothermia in critically ill trauma patients. Injury 1998; 29(8): 605-8.

Rotondo MF, Schwab CW, McGonigal MD, et al. 'Damage control': an approach for improved survival in exsanguinating penetrating abdominal injury. F Trauma 1993; 35 (3): 375-83.

Rotondo MF. Damage control. In: The Trauma Manual. 1998. Eds. Peitzman AB, Rhodes M, Schwab CW, Yealy DM. Lippincott-Raven. Ch 27B; 275-80. Sarmiento JM, Yugueros P, Garcia AF, Wolff BG. Bullets and their role in sepsis after colon wounds. World $\mathcal{F}$ Surg 1997; 21 (6): 648-52.

Schein M, Wittmann DH, Aprahamian CC, et al. The abdominal compartment syndrome: The physiological and clinical consequences of elevated intra-abdominal pressure. F Am Coll Surg 1995; 180 (6): 745-753.

Seekamp A, Ziegler M, Van Griensven M, GrotzM, Regel G. The role of hypothermia in trauma patients. Eur f of Emerg Med 1995; 2(1): 28-32.

Udekwu AO, Gammie JS, Schwab CW. Care of the pregnant trauma patient. In: The Trauma Manual. 1998. Eds. Peitzman AB, Rhodes M, Schwab CW, Yealy DM. Lippincott-Raven. Ch 44; 443-50.

Van Der Spuy JW, Knottenbelt JD, Kottler RE. Subpulmonary haemothorax: 387 cases. Injury 1991; 22 (5): $385-90$. 
Velmahos GC, Demetriades D, Chan L, et al. Predicting the need for thoracoscopic evacuation of residual traumatic hemothorax: chest radiograph is insufficient. fTrauma 1999; 46 (1): 65-70.

Waxman K, Annans C, Daughters K, Tominaga GT, Scannell G. A method to determine the adequacy of resuscitation using tissue oxygen monitoring. F Trauma 1994; 36 (6): 852-8.

Westaby S, Stephenson M. Penetrating injuries to chest and abdomen. In: Trauma, Pathogenesis and Treatment, 1989. Ed. Westaby S. Heinmann Medical Books. Ch 12; 159-80.
Wilson RF. General considerations in abdominal trauma. In: Handbook of Trauma. 1999. Ed. Wilson RF. Lippincott Williams \& Wilkins. Ch 20; pp311-328. Wilson RF. Thoracic trauma: chest wall and lung. In: Handbook of Trauma, 1999. Ed. Wilson RF. Lippincott Williams \& Wilkins. Ch 16; 228-45.

Wilson RF. Thoracic trauma: heart. In: Handbook of Trauma. 1999. Ed. Wilson RF. Lippincott Williams \& Wilkins. Ch 17; 246-265. 